\title{
Study of knowledge and practices of hand washing among mothers having children under 5 years of age in urban field practicing area of Kakatiya Medical College, Warangal, Telangana, India
}

\author{
Rafath Unnisa Begum*, K. Bhavani
}

Department of Community Medicine, Kakatiya Medical College, Warangal, Telangana, India

Received: 05 July 2016

Accepted: 19 July 2016

\section{*Correspondence:}

Dr. Rafath Unnisa Begum,

E-mail: dr.rafathunnisa@gmail.com

Copyright: (C) the author(s), publisher and licensee Medip Academy. This is an open-access article distributed under the terms of the Creative Commons Attribution Non-Commercial License, which permits unrestricted non-commercial use, distribution, and reproduction in any medium, provided the original work is properly cited.

\begin{abstract}
Background: Hand washing is viewed as most cost effective intervention for reducing global infections like diarrhoea, acute respiratory tract infections. According to WHO estimates, 3.8 million children aged less than five die each year from diarrhoea and ARI. WHO defines hand washing as washing hands with soap and water (HWWS) thoroughly following the five critical moments i.e. after defecation, after cleaning child's bottom who had defecated, before cooking, eating and feeding child. Objectives of the study was to study the socio demographic profile of mothers, to study the hand washing practices among mothers having children under 5 years of age and factors influencing them and to impart knowledge about the importance of hand washing

Methods: A community based descriptive cross sectional study was undertaken on mothers randomly selected in rangampet, urban field practising area of KMC, Warangal. A total of 150 mothers were interviewed using a predesigned semi-structured questionnaire. The data was analyzed using SPSS version 22.00.

Results: Mothers who washed their hands with soap and water after defecation $(79.3 \%)$ and after cleaning child's bottom $(82.7 \%)$ before cooking $(44.7 \%)$, before eating $(44.7 \%)$ and before feeding the child $(41.3 \%)$. The women who didn't wash their hands properly (used only water) after defecation (20.7\%) and after cleaning a child who has just defecated $(17.3 \%$ ) cited the absence of soap or water at the designated site of hand washing as the reason for not doing so. $78.7 \%$ have told that hand washing is important in prevention of diseases. $16.7 \%$ have given the response that they don't know the importance of hand washing.

Conclusions: The study shows hand washing after critical moments is critically low. It can be suggested that interventions by educating target an increase in hand washing practices. Innovative social marketing approaches may help in adoption of proper hand washing behaviour.
\end{abstract}

Keywords: ARI, Critical moments, Diarrhoea, HWWS, Social marketing approach

\section{INTRODUCTION}

Hand washing: clean hand saves lives is defined as physical removal of micro-organisms from the hands using soap (plain or antimicrobial) and running water. According to WHO estimates, 3.8 million children aged less than five die each year from diarrhoea and ARI. An estimated $88 \%$ of diarrheal deaths worldwide are attributable to unsafe water, inadequate sanitation and poor hygiene. Clean water and hand washing are viewed as the most cost effective intervention for preventing diarrheal diseases and ARIs. According to WHO, proper handwashing was defined as washing hands with soap and water (HWWS) thoroughly following the five critical 
moments i.e., after defecation, after cleaning child's bottom who had defecated, before cooking, before eating and before feeding child. half of all the child deaths occur each year are due to diarrhoea and acute respiratory infections, both of which are transmitted from person to person during everyday interaction, through droplet and airborne spread, through skin contact and through contamination of the environment. ${ }^{1}$ Current epidemiological evidence indicates that HWWS prevents about $30-47 \%$ of child diarrhoeas and $23 \%$ of respiratory infections. $^{2-5}$ Hands are washed with soap only about 5$15 \%$ of key occasions (such as after the toilet or after cleaning up a child). ${ }^{6}$ Objectives of the study was to study the socio-demographic profile of mothers, to study the hand washing practices among mothers having children under 5 years of age and to impart knowledge about the importance of handwashing.

\section{METHODS}

The urban areas of Kakatiya Medical College divided into 3 sub divisions called Rangampet, Tummalkunta and Peddammagadda of which Rangampet formed the study setting. A cross-sectional study was carried out between August to October 2015. A total of 150 mothers were selected conveniently due to feasibility reasons. The mothers were explained about the purpose and utility of the survey, informed oral consent was obtained from each participant and interviewed by administering predesigned semi structured questionnaire which was used to collect data regarding the socio-demographic profile \& hand washing knowledge and practices. The study tool was developed following a meticulous appraisal of literature and validated by expert review. The data was entered into Microsoft Excel and analyzed using Statistical Package of Social Sciences (SPSS) version 22.00, frequency and percentages were reported to explore the socio-demographic profile and handwashing practices amongst the respondents. Chi-square test was used to find out the association between sociodemographic variables on handwashing practices following the critical moments. Statistical significance was set at $\mathrm{p}$-values $\leq 0.05$.

\section{RESULTS}

As Table 1 shows that among all participants mothers were between 20-25 years with Mean age of 25 years and $40 \%$ were illiterates and $48.5 \%$ were unemployed, $61.3 \%$ were Hindus belonging to upper middle class, $48.3 \%$ have pacca house with $50 \%$ staying in joint family. Among them only $74 \%$ have toilets at home and $54.7 \%$ have handwash area at home and only $54.7 \%$ people have availability of soap at hand wash area.

As Table 2 shows that majority of the mothers wash their hands with soap and water after defecation $(79.3 \%)$ and after cleaning child's bottom $(82.7 \%)$ before cooking (44.7\%), before eating $(44.7 \%)$ and before feeding the child $(41.3 \%)$.
Table 1: Socio-demographic profile of study population.

\begin{tabular}{|ll|}
\hline Socio-demographic profile & No. $(\%)$ \\
\hline Age of Mothers ( In Years) & \\
$<20$ & $09(6.0 \%)$ \\
$20-25$ & $85(56 \%)$ \\
$26-30$ & $45(30 \%)$ \\
$>30$ & $11(7.3 \%)$ \\
\hline Education & \\
Illterate & $60(40.0 \%)$ \\
Schooling & $29(19.3 \%)$ \\
Intermediate & $11(7.3 \%)$ \\
Graduates & $50(33.4 \%)$ \\
\hline Occupation & \\
Professional & $05(3.3 \%)$ \\
Semiprofessionals & $02(1.3 \%)$ \\
Skilled & $43(28.7 \%)$ \\
Unskilled & $27(18.0 \%)$ \\
Unemployed & $73(48.7 \%)$ \\
\hline Religion & \\
Muslim & $31(20.7 \%)$ \\
Hindu & $92(61.3 \%)$ \\
Christian & $27(18 \%)$ \\
\hline Percapita income & \\
Upper middle & $68(54.7 \%)$ \\
Middle & $68(45 \%)$ \\
Lower middle & \\
\hline Type of house & \\
Pacca & \\
Semipacca & \\
Kaccha & $35(30.0 \%)$ \\
\hline Type of family & $39(24.7 \%)$ \\
Nuclear family & \\
Joint family & $68(48.3 \%)$ \\
Extended family & $45(30.0 \%)$ \\
\hline Toilet status at home & $37(24.7 \%)$ \\
Yes & \\
No & $73(48.7 \%)$ \\
\hline Hand wash area & $01(0.7 \%)$ \\
Yes & \\
No & \\
\hline Location of hand wash area & \\
Bathroom & \\
Outside & \\
\hline Soap availability at hand wash & \\
area & \\
Yes & \\
No & \\
\hline & \\
\hline
\end{tabular}

The women who didn't wash their hands properly (used only water) after defecation $(20.7 \%)$ and after cleaning a child who has just defecated $(17.3 \%$ ) cited the absence of soap or water at the designated site of hand washing as the reason for not doing so as Table 3 shows that mothers who told hand washing is important in prevention of diseases was $(78.7 \%)$ and who dint know was $(11.3 \%)$ and mothers who told ARI is prevented were (22\%), both ARI and diarrhoea (22\%), only diarrhoea (17.3\%), 
allergy $(7.3 \%)$, multiple answers were given by $(14 \%)$ and $(16.7 \%)$ told that they do not know about the diseases prevented.

Table 2: Hand washing knowledge and practices among study population.

\begin{tabular}{|lll|}
\hline $\begin{array}{l}\text { Hand washing } \\
\text { practices among } \\
\text { mothers }\end{array}$ & $\begin{array}{l}\text { With water and } \\
\text { soap }\end{array}$ & $\begin{array}{l}\text { With water } \\
\text { only }\end{array}$ \\
\hline Before cooking & $67(44.7 \%)$ & $83(55.3 \%)$ \\
\hline Before eating & $67(44.7 \%)$ & $83(55.3 \%)$ \\
\hline Before feeding & $62(41.3 \%)$ & $88(58.7 \%)$ \\
\hline $\begin{array}{l}\text { After own } \\
\text { defecation }\end{array}$ & $119(79.3 \%)$ & $31(20.7 \%)$ \\
\hline $\begin{array}{l}\text { After child } \\
\text { defecation }\end{array}$ & $124(82.7 \%)$ & $26(17.3 \%)$ \\
\hline
\end{tabular}

As Table 4 shows that $70 \%$ mothers told that hand washing is important in prevention of diseases out of which only $26 \%$ are graduates. $21 \%$ mothers have responded that they don't know the importance of hand washing.

As Table 5 shows that when association was found between soap availability at wash area and HWWS after defecation $\mathrm{p}$ value was found to be 0.001 and soap availability at wash area and HWWS after child defecation $\mathrm{P}$ value was found to be 0.001 which is highly significant.

As Table 6 shows that the p-value was found to be 0.001 between location of wash area and HWWS after defecation and after child defecation which was found to be highly significant.

Table 3: Knowledge about hand washing amongst study population.

\section{Participants who told hand washing is imp in prevention of diseases}

Yes

No

Don't know

Diseases prevented by hand washing-

ARI

ARI \& diarrhoea

Diarrhoea

Allergy

Multiple diseases

Don't know

\section{No. $(\%)$ \\ $118(78.7 \%)$ \\ $15(10 \%)$ \\ $17(11.3 \%)$}

$33(22 \%)$

$33(22 \%)$

$26(17.3 \%)$

$11(7.3 \%)$

$21(14 \%)$

$25(16.7 \%)$

Table 4: Determinants of hand washing practices amongst study population.

\begin{tabular}{|lllll|}
\hline Education & \multicolumn{2}{l}{ Important in prevention of diseases } & \multicolumn{2}{l|}{ Total } \\
& Yes & No & Don't know & \\
\hline Illiterate & $39(26 \%)$ & $14(9 \%)$ & $7(5 \%)$ & $60(40 \%)$ \\
\hline Schooling & $16(11 \%)$ & $6(4 \%)$ & $9(6 \%)$ & $31(20.6 \%)$ \\
\hline Intermediate & $11(7 \%)$ & 0 & 0 & $11(7 \%)$ \\
\hline Graduate & $39(26 \%)$ & $5(3.3 \%)$ & $5(3.3 \%)$ & $49(33 \%)$ \\
\hline Total & $105(70 \%)$ & $25(16 \%)$ & $21(14 \%)$ & $150(100 \%)$ \\
\hline
\end{tabular}

Table 5: Soap availability at wash area in relation to HWWS after own defection and after child's defecation.

\begin{tabular}{|c|c|c|c|}
\hline \multirow[t]{2}{*}{ Soap availability at wash area } & \multicolumn{3}{|c|}{ HWWS after defecation } \\
\hline & Yes & No & P-value \\
\hline Yes & 78 & 4 & \multirow{3}{*}{0.001} \\
\hline No & 41 & 27 & \\
\hline Total & 119 & 31 & \\
\hline \multirow[t]{2}{*}{ Soap availability at wash area } & \multicolumn{2}{|c|}{ HWWS after child defecation } & \multirow[b]{2}{*}{ P-value } \\
\hline & Yes & No & \\
\hline Yes & 80 & 2 & \multirow{3}{*}{0.001} \\
\hline No & 44 & 24 & \\
\hline Total & 124 & 26 & \\
\hline
\end{tabular}


Table 6: Location of wash area in relation to HWWS after defecation and after child's defecation.

\begin{tabular}{|c|c|c|c|}
\hline \multirow{2}{*}{ Location of wash area } & \multicolumn{2}{|c|}{ HWWS after defecation } & \multirow{2}{*}{ P-value } \\
\hline & Yes & No & \\
\hline Bathroom & 81 & 3 & \multirow{3}{*}{0.001} \\
\hline Outside & 38 & 28 & \\
\hline Total & 119 & 31 & \\
\hline \multirow{2}{*}{ Location of wash area } & \multicolumn{2}{|c|}{ HWWS after child defecation } & \multirow{2}{*}{ P-value } \\
\hline & Yes & No & \\
\hline Bathroom & 83 & 1 & \multirow{3}{*}{0.001} \\
\hline Outside & 41 & 25 & \\
\hline Total & 124 & 26 & \\
\hline
\end{tabular}

\section{DISCUSSION}

Majority of the mothers wash their hands with soap and water after defecation (79.3\%) and after cleaning child's bottom $(82.7 \%)$ before cooking $(44.7 \%)$ in contrast to the results obtained in this study done by Scott $\mathrm{BE}$ et al. ${ }^{7}$ before eating $(44.7 \%)$ and before feeding the child $(41.3 \%)$ which is lower than washing hands after defecation and after child defecation and results were similar obtained by study done by Rabbi SE in Bangladesh. ${ }^{8}$ The women who didn't wash their hands properly (used only water) after defecation (20.7\%) and after cleaning a child who has just defecated (17.3\%) cited the absence of soap or water at the designated site of hand washing as the reason for not doing so. Mothers who told hand washing is important in prevention of diseases was (78.7\%) and who didn't know was (11.3\%) in contrast to the results obtained by study done by $\mathrm{K}$. Seema et al, ${ }^{9}$ Where $96.7 \%$ mothers know that hand washing is important in prevention of diseases and mothers who told ARI is prevented were $(22 \%)$, both ARI \& diarrhoea (22\%), only diarrhoea (17.3\%), allergy $(7.3 \%)$, multiple answers were given by $(14 \%)$ and $(16.7 \%)$ told that they do not know about the diseases prevented.

In another study done by Pandve HT et al. ${ }^{10}$ Revealed that almost $80 \%$ of the study participants used water with soap for hand washing. Around $12 \%$ were using only water for hand washing. All the study participants $(100 \%)$ were practicing hand washing after defecation, while $95 \%$ study participants were practicing hand washing before and after handling any food item. The present study also showed an association between location of the designated place for hand washing and soap availability with the practice of HWWS after defecation and after cleaning the child who had defecated. In a study done by Luby SP et al. ${ }^{11}$ Presence of water and soap at the designated place to wash hands were significantly associated with washing hands with soap after fecal contact. Mother's education was associated with HWWS after defecation and after cleaning child's bottom. Past studies have reported similar findings from Bangladesh by Rabbi et al and
Luby $\mathrm{S}$ et al and from Ghana by Scott et al in contrast to the study done by Biran A et al. ${ }^{1,2,5,12}$ Which showed that there is no association between mothers education and HWWS after defecation and after cleaning child's bottom. The present study had some limitations. The results of this study could be generalized as convenient sampling was done.

\section{Recommendations}

It was found that there is lack of knowledge among mothers about hand washing. The knowledge gap among the mothers regarding the benefits of handwashing in reducing diarrhoeal and ARI episodes of the children could be tackled by intensive health education activities. Innovative social marketing approaches may help in adoption of hand washing behaviour.

\section{ACKNOWLEDGEMENTS}

We would like to express our sincere gratitude to Dr. Punam Kumari Jha, Professor and Head, and Dr. K. J. Kishore Kumar, Associate Professor, Dept. of Community Medicine, Kakatiya Medical College, Warangal and also my sincere thanks to all the participants of our study.

\section{Funding: No funding sources}

Conflict of interest: None declared

Ethical approval: The study was approved by the Institutional Ethics Committee

\section{REFERENCES}

1. WHO. World Health Report 2002. Geneva: World Health Organization, 2002.

2. Curtis V, Cairncross S. Effect of washing hands with soap on diarrhoea risk in the community: a systematic review. Lancet Infect Dis. 2003;3:27581.

3. Ejemot RI, Ehiri JE, Meremikwu MM. Hand washing for preventing diarrhoea. Cochrane Database Syst Rev. 2008:1. 
4. Rabie T, Curtis V. Evidence that handwashing prevents respiratory tract infection: a systematic review. Trop Med Int Health. 2006;11:1-10.

5. Luby S, Agboatwalla M, Feikin D et al. Effect of handwashing on child health: a randomised controlled trial. Lancet. 2005;366:225-33.

6. Jamieson D, Bremen J, Measham A. Disease Control Priorities in Developing Countries. Oxford: Oxford University Press, 2006. Rences. 2006.

7. Scott BE, Lawson DW, Curtis V. Hard to handle: understanding mothers' hand washing behavior in Ghana. Health Policy and Planning. 2007;22:21622.

8. Rabbi SE, Dey NC. Exploring the gap between hand washing knowledge and practices in Bangladesh: a cross sectional study. BMC Public Health 2013;13:89.

9. Aithal KS, Ogorchukwu MJ. Hand washing knowledge and practice among mothers of underfive children in coastal Karnataka, India - A crosssectional study. Int $\mathrm{J}$ Med Health Sci. 2014;3(4):266-71.
10. Pandve HT, Chawla PS, Giri PA, Fernandez K, Singru SA. Study of hand washing practices in rural community of Pune, India. Int J Community Med Public Health. 2016;3:190-93.

11. Luby SP, Halder AK, Tronchet C, Akhter S, Bhuiya A, Johnston RB. Household characteristics associated with handwashing with in rural Bangladesh. Am J Trop Med Hyg. 2009;81(5):88287.

12. Biran A, Schmidt WP, Wright R, Jones T, Seshadri $\mathrm{M}$, Isaac $\mathrm{P}$ et al. The effect of a soap promotion and hygiene education campaign on handwashing behavior in rural India: a cluster randomized trial. Trop Med and Int Health. 200;14(10):1303.

Cite this article as: Rafath UB, Bhavani K. Study of knowledge and practices of hand washing among mothers having children under 5 years of age in urban field practicing area of Kakatiya Medical College, Warangal, Telangana, India. Int J Community Med Public Health 2016;3:2035-9. 